\title{
The prognosis of depression in the elderly
}

\author{
Martin G. Cole, MD, FRCPC
}

Controversy prompted a systematic and critical review of original research articles to determine the prognosis of depression in the elderly. A search of three computer databases for articles published from January 1980 to May 1989 and of the bibliographies of articles located revealed 10 reports, involving 990 subjects, that met the following inclusion criteria: original research, published in English or French since 1950, sample of at least 25 patients, inclusion of only patients over 60 years, mean follow-up period of 1 year or more and description of the patients' mental state during follow-up. The methods and study designs were then assessed with the use of the criteria for prognostic studies established by McMaster University Health Sciences Centre, Hamilton, Ont. All of the studies had serious, multiple flaws. Nevertheless, when the results were combined it appeared that at least $60 \%$ of the patients remained well or had relapses with recovery (mean follow-up 31.9 months); up to $25 \%$ remained continuously ill. Physical illness, cognitive impairment and severe depressive symptoms were frequently related to poor prognosis; most of the social factors studied were not related to prognosis. Future studies must pay attention to methods and design, particularly the composition of study populations, the assessment of outcomes and the control of extraneous prognostic factors.

La controverse a donné lieu à un examen systématique et critique d'articles basés sur une recherche originale, afin de déterminer le pronostic de la dépression chez les personnes âgées. Dans trois banques de données nous retraçons les articles publiés de janvier 1980 à mai 1989 ainsi que leurs bibliographies qui nous révèlent que 10 travaux originaux réunissant 990 sujets sont parus en anglais ou en français depuis 1950, chacun portant sur au moins 25 malades, tous âgés d'au moins 60 ans et dont on décrit l'état mental avec un recul moyen d'au moins 1 an. Nous avons évalué le plan et les méthodes d'analyse de chacun de ces travaux en fonction des critères relatifs aux études pronostiques établis à la McMaster University Health Sciences Centre de Hamilton (Ont.). À cette lumière, tous ces 10 travaux présentent de nombreuses lacunes graves. Il semble cependant, sur la foi de leurs résultats combinés, qu'au moins $60 \%$ des malades en post-cure sont restés bien portants ou du moins, s'ils ont rechuté, ont recouvré la santé; les malades ont été suivis sur une moyenne de 31,9 mois. Quelque $25 \%$ des sujets sont restés continuellement déprimés. Les maladies somatiques, les troubles cognitifs et la profondeur de la dépression étaient souvent rattachés à un mauvais pronostic; pour la plupart, les facteurs sociaux qui ont été considérés n'influaient pas sur celui-ci. Les travaux devront, dans l'avenir, être mieux conçus, surtout quant à la composition des groupes de malades à l'étude, à l'examen des issues et à la considération des variables pouvant influer sur celles-ci.

$\mathrm{T}$ raditional views of the prognosis of depression are usually traced to Kraepelin, ${ }^{1}$ who stated that the prognosis of manic depressive insanity was favourable for the individual episode but that repeated episodes or even eventual intractable illness could occur. In Kraepelin's series of 440 patients with depression alone $58 \%$ had one episode only, $29 \%$ had two episodes and $13 \%$ had three or

Dr. Cole is psychiatrist-in-chief and director, Division of Psychogeriatrics, St. Mary's Hospital, and associate professor, Department of Psychiatry and Centre for Studies on Aging, McGill University, Montreal. 
more episodes. Significantly, less than $11 \%$ of the patients were over 60 years of age, and less than $2 \%$ were over 70 .

Reports of prognostic studies of depression in the elderly and review articles on these reports have since been published. Unfortunately, the authors came to very different conclusions. For example, Millard $^{2}$ concluded that the prognosis is relatively poor: "No matter what is done, one-third get better, one-third stay the same and one-third get worse." On the other hand, Baldwin ${ }^{3}$ concluded that the prognosis is relatively good: "More than $60 \%$ of cases remain either relapse free or have relapses that are successfully treated." Because of these contradictory conclusions and potentially serious management implications I reviewed systematically and critically all recent original research reports to determine the prognosis of depression in the elderly. This review process, modified from one described by Oxman and Guyatt, ${ }^{4}$ involved systematic selection of original studies, assessment of their validity and examination of their results.

\section{Selection of articles}

Systematic selection involved three steps: first, three computer databases (MEDLINE, Psychological Abstracts and Mental Health Abstracts) were searched for all relevant original research articles published from January 1980 to May 1989; the key words "prognosis", "depression" and "elderly" were used. Second, the bibliographies of the retrieved articles were searched for additional references. Finally, all the articles collected were screened to meet the following six inclusion criteria: original research study, published in English or French after 1950, sample of at least 25 patients, inclusion of only patients over 60 years of age, mean follow-up period of 1 year or more and description or classification of patients' mental state during the follow-up period. This selection process yielded 10 studies, involving 990 patients (Table 1). ${ }^{5-14}$

Different diagnostic criteria for depression were used to enrol subjects in the 10 studies: in one ${ }^{5}$ the criteria of Roth ${ }^{15}$ were used, in two $^{6.7}$ those of

\begin{tabular}{|c|c|c|c|c|c|c|c|}
\hline \multirow[b]{2}{*}{ Article } & \multirow{2}{*}{$\begin{array}{l}\text { No. of } \\
\text { patients }\end{array}$} & \multirow{2}{*}{$\begin{array}{l}\text { Age (and } \\
\text { mean), yr }\end{array}$} & \multicolumn{2}{|c|}{$\begin{array}{l}\text { Sex; no. of } \\
\text { patients }\end{array}$} & \multirow[b]{2}{*}{ Population } & \multirow{2}{*}{$\begin{array}{l}\text { Length of } \\
\text { follow-up } \\
\text { (and mean), mo }\end{array}$} & \multirow{2}{*}{$\begin{array}{c}\text { Outcome } \\
\text { and } \% \text { of patients }\end{array}$} \\
\hline & & & Female & Male & & & \\
\hline Kay et al, $1955^{5}$ & 175 & $\geq 60(68)$ & 117 & 58 & Inpatients & $9-27(20.5)$ & $\begin{array}{l}\text { Well } 38, \text { relapse } 18, \text { ill } 29 \\
\text { died } 15\end{array}$ \\
\hline Post, $1962^{6}$ & $100^{*}$ & $\geq 60$ & 53 & 47 & Inpatients & 72 & $\begin{array}{l}\text { Lasting recovery } 31 \text {, relapse } \\
\text { with recovery } 28, \text { symptoms } \\
\text { or relapse } 23 \text {, ill } 17^{7}\end{array}$ \\
\hline Post, $1972^{7}$ & 92 & $\geq 60$ & - & - & Inpatients & 36 & $\begin{array}{l}\text { Lasting recovery } 26 \text {, relapse } \\
\text { with recovery } 37 \text {, symptoms } \\
\text { or relapse } 25 \text {, continuously } \\
\text { ill } 12\end{array}$ \\
\hline Gordon, $1981^{8}$ & 74 & $\geq 65$ & 57 & 17 & Inpatients & 12 & Symptom free 64 , relapse $15 \dagger$ \\
\hline Murphy, $1983^{\circ}$ & 124 & $65-89$ & 88 & 36 & $\begin{array}{l}\text { Inpatients } \\
\text { Outpatients }\end{array}$ & 12 & $\begin{array}{l}\text { Well } 35 \text {, relapse } 19, \\
\text { continuously ill } 29 \\
\text { dementia } 3 \text {, died } 14\end{array}$ \\
\hline Cole, $1983^{10}$ & 38 & $65-88(70)$ & 28 & 10 & Inpatients & $7-31(18)$ & $\begin{array}{l}\text { Completely well } 41 \text {, tolerably } \\
\text { well } 25 \text {, ill } 22 \text {, died } 12\end{array}$ \\
\hline Cole, $1985^{11}$ & 60 & $65-92(71)$ & 38 & 22 & Outpatients & $24-63(48)$ & $\begin{array}{l}\text { Completely well } 18 \text {, tolerably } \\
\text { well } 52 \text {, ill } 30\end{array}$ \\
\hline \multirow[t]{2}{*}{$\begin{array}{l}\text { Baldwin et al, } \\
1986^{12}\end{array}$} & 100 & $65-88(74)$ & 79 & 21 & Inpatients & 12 & $\begin{array}{l}\text { Well } 58 \text {, relapse } 15 \text {, residual } \\
\text { symptoms or continuously } \\
\text { ill } 18 \text {, died } 8\end{array}$ \\
\hline & & & & & & $42-104$ & $\begin{array}{l}\text { Lasting recovery } 22 \text {, relapse } \\
\text { with recovery } 39 \text {, depres- } \\
\text { sive invalidism } 32 \text {, } \\
\text { continuously ill } 7\end{array}$ \\
\hline $\begin{array}{c}\text { Godber et al, } \\
1987^{13}\end{array}$ & 163 & $\geq 65(76)$ & 120 & 43 & Inpatients & 36 & $\begin{array}{l}\text { No relapse } 33 \text {, relapse with } \\
\text { good recovery } 28 \text {, relapse } \\
\text { with poor recovery } 34 \text {, } \\
\text { other } 5\end{array}$ \\
\hline $\begin{array}{l}\text { Magni et al, } \\
1988^{14}\end{array}$ & 64 & $68-82$ & 45 & 19 & Outpatients & 12 & Well 31, ill 69 \\
\hline
\end{tabular}

"Includes 19 patients with dementia.

tInformation on remaining patients was unavailable. 
"depressive symptoms", in six $^{8-13}$ the Feighner research diagnostic criteria ${ }^{16}$ and in one ${ }^{14}$ the DSM-III criteria. ${ }^{17}$ Furthermore, most of the studies enrolled subjects with several depressive subtypes (e.g., unipolar depression and atypical depression). Because there is no solid evidence of a relation between diagnostic criteria or depressive subtypes and the course of depressive illness in the elderly the presence of particular diagnostic criteria or particular depressive subtypes was not considered an inclusion criterion for my review.

\section{Assessment of validity}

To determine the validity of the studies the methods and design of each study were assessed with the use of the criteria described by the Department of Clinical Epidemiology and Biostatistics, McMaster University Health Sciences Centre, Hamilton, Ont. (Table 2). ${ }^{18}$ These criteria are as follows: formation of an inception cohort, description of referral pattern, completion of follow-up, development and use of objective outcome criteria, blind outcome assessment and adjustment for extraneous prognostic factors.

\section{Formation of an inception cohort}

Depression in elderly patients should be identified at an early and uniform point in its course so that patients who recover completely or die are included with those who suffer a relapse or whose depression persists. Patients with multiple relapses or chronic depression might be included more than once; thus, the prognosis of depression would appear worse than it really is. Ideally, only elderly patients experiencing a first lifetime episode of depression or at least a first episode of depression in old age should be included.

Nine $e^{5,8,10-14}$ of the 10 studies did not meet this criterion. The inception cohort was formed of consecutive referrals, consecutive admissions or consecutive discharges, and one study ${ }^{13}$ included only referred patients treated with electroconvulsive therapy. Consequently, in the nine studies the inception episode represented the first lifetime episode of depression in $27 \%$ to $65 \%$ of the cases and in one study $^{12}$ the first episode in old age in $79 \%$ of the cases. Murphy's study ${ }^{9}$ was the exception: subjects aged over 65 years were included only if the inception episode represented the first one after age 60 , so that all of the study patients were experiencing a first episode of depression in old age.

\section{Description of referral pattern}

The pathways by which patients enter a study sample should be described. Three types of sample bias can distort prognostic studies of depression: centripetal bias, in which experts are referred problem cases; popularity bias, in which experts preferentially follow interesting cases; and referral filter bias, in which secondary or tertiary care services receive cases different from those in the general population.

None of the 10 studies described adequately the referral patterns or the potential sample biases. Murphy ${ }^{9}$ provided some information about the referral pattern. Godber and associates ${ }^{13}$ described their catchment area but not the pattern of referral to their service.

\section{Completion of follow-up}

All members of the inception cohort should be accounted for at the end of the follow-up period. McMaster ${ }^{18}$ proposed that a loss of more than $20 \%$ of the study cohort is unsatisfactory.

Accordingly, follow-up was completed satisfactorily in all but one study, ${ }^{14}$ in which at least $32 \%$ of the inception cohort was lost to follow-up.

\begin{tabular}{|c|c|c|c|c|c|c|}
\hline \multirow[b]{2}{*}{ Study } & \multicolumn{6}{|c|}{ Inclusion criteria } \\
\hline & $\begin{array}{l}\text { Formation } \\
\text { of inception } \\
\text { cohort }\end{array}$ & $\begin{array}{l}\text { Description } \\
\text { of referral } \\
\text { pattern }\end{array}$ & $\begin{array}{l}\text { Completion } \\
\text { of follow-up }\end{array}$ & $\begin{array}{l}\text { Development } \\
\text { and use of } \\
\text { objective } \\
\text { outcome criteria }\end{array}$ & $\begin{array}{l}\text { Blind outcome } \\
\text { assessment }\end{array}$ & $\begin{array}{l}\text { Adjustment for } \\
\text { extraneous } \\
\text { prognostic factors }\end{array}$ \\
\hline Kay et $\mathrm{al}^{5}$ & - & - & + & - & - & $+1-$ \\
\hline Post $^{6}$ & - & - & + & - & - & $+1-$ \\
\hline Post $^{7}$ & - & - & + & - & - & $+1-$ \\
\hline Gordon" & - & - & + & - & - & - \\
\hline Murphy ${ }^{9}$ & + & $+1-$ & + & - & - & $+1-$ \\
\hline $\mathrm{Coll}^{10}$ & - & - & + & - & - & + \\
\hline Cole $^{11}$ & - & - & + & $+1-$ & - & $+1-$ \\
\hline Baldwin et al' & - & - & + & - & - & $+1-$ \\
\hline Godber et $\mathrm{al}^{13}$ & - & $+1-$ & + & - & - & - \\
\hline Magni et al ${ }^{14}$ & - & - & - & - & - & $+1-$ \\
\hline
\end{tabular}


Development and use of objective outcome criteria

Prognostic outcomes should be stated in explicit and objective terms to enable readers to relate the results to their experience. Also, there should be reassurance that the outcome criteria were applied in a reliable and consistent manner.

Although all of the studies reported outcomes in one of two to eight categories (from "completely well" to "chronically ill") the criteria for assignment to these categories were vague and imprecise. In only one study ${ }^{13}$ was relapse defined. Moreover, in all the studies it was impossible to distinguish patients with few and brief relapses from those with frequent and prolonged relapses. In one of my studies ${ }^{11}$ I tried to address this quantitative issue by calculating the proportion of time well during the follow-up period. Finally, there was no evidence in any of the studies that the patients were assigned reliably and consistently to outcome categories (i.e., there was no calculation of agreement between the raters on category assignment).

\section{Blind outcome assessment}

Outcome should be assessed by clinicians who are blind to potentially important prognostic events. Judgements about outcome can be dramatically influenced by knowledge of previous clinical features or expectations about the course of depression. In this respect, the outcome assessment was not blind in any of the 10 studies.

\section{Adjustment for extraneous prognostic factors}

To determine the prognosis of depression in the elderly, interference from other factors (e.g., disability, physical illness, cognitive impairment, social factors and treatments) that might affect the prognosis should be eliminated or at least accounted for.

None of the investigators eliminated the influence of disability on the prognosis. In one study ${ }^{10}$ the effect of both physical illness and cognitive impairment was eliminated. In seven $5-7.9,11,12.14$ the influences of disability, physical illness and cognitive impairment were examined but not eliminated. Kay, Roth and Hopkins $s^{5}$ used psychometric tests to assign patients with depression to categories of mixed, doubtful or no organicity and determined the prognosis independently in the three groups. Post $^{6}$ assigned patients to categories of no, doubtful or definite cognitive impairment and determined the outcome; also, the influence of physical defects and disabilities on outcome were measured. In a later study Post $^{7}$ examined the influence of disabling physical illness. Murphy ${ }^{9}$ excluded patients with definite cognitive impairment and examined the relation of physical health to prognosis. I considered the effect of minor organic signs and moderate physical disability on prognosis. ${ }^{11}$ Baldwin and Jolley ${ }^{12}$ excluded patients with organic brain syndromes and examined the relation of initial health problems and further health changes to prognosis. Finally, Magni, Palazzolo and Bianchin ${ }^{14}$ considered the influence of physical illness and diseases of the central nervous system on the course and outcome of depression.

In six studies ${ }^{6.9-12.14}$ the effect of social factors on prognosis were considered, but these factors were not eliminated or accounted for. The social factors included marital status, living circumstances (i.e., household composition), social class, income, property ownership, employment, activities, number of social contacts, precipitating severe life events (e.g., loss of loved one, personal illness), intervening severe life events, major social difficulties (e.g., housing, finances and children) and the presence of an intimate, confiding relationship.

In nine of the studies ${ }^{6-14}$ the types of treatments received by the study patients as a group were described briefly. No study controlled for treatments or related treatments to prognosis.

\section{Examination of the results}

Assessment of the validity of the 10 articles revealed serious and multiple flaws in their methods and designs (Table 2). Consequently, their results are questionable. Not even one study was methodologically sound enough to serve as a benchmark in evaluating the results of the others.

Despite the questionable validity the results were examined. The samples were 38 to 175 patients. The patients' ages were 60 to 92 years; six studies reported the mean age (68 to 76 years). Nine reported sex; $21 \%$ to $47 \%$ of the patients were men. Only inpatients were included in seven studies, only outpatients in two and both in one. The length of follow-up was 6 to 104 (mean 31.9) months.

The studies were separated into two groups according to length of follow-up. The first group included six studies $5,8-10,12.14$ with a mean follow-up of 24 months or less, and the second included five studies $^{6,711-13}$ with a mean follow-up of more than 24 months. (The study by Baldwin and Jolley ${ }^{12}$ had follow-up periods of 12 months and 42 to 104 months.) The mean follow-up period for the first group was 14.4 months and for the second 53 months.

The prognostic outcomes in the two follow-up groups are in Table 1. Only three outcome categories were consistent across most of the studies: "well", "relapse with recovery" and "continuously ill". The 
other outcomes (e.g., died, relapse, lost to follow-up, unknown and other) were classified as "other" in this analysis. The ranges of outcomes and the combined prognostic outcomes (meta-analysis) in the two follow-up groups are in Table 3.

In eight studies ${ }^{5-7,9-12,14}$ the investigators attempted to identify prognostic factors, although the definition and measurement of these factors varied from one study to the next. Poor prognosis was associated with cognitive impairment in three studies, ${ }^{5,6,14}$ with physical illness in five $e^{6,7,9,11,12}$ but not in one, ${ }^{14}$ with onset of the first depressive episode before 60 years of age in two ${ }^{5,10}$ but not in two others, ${ }^{6,7}$ and with advanced patient age in two 6,9 but not in four. ${ }^{9-12}$ Severity of depressive symptoms was identified as a poor prognostic factor in four studies, ${ }^{6,7,9,12}$ as were poor treatment compliance ${ }^{11}$ and development of further physical illness. ${ }^{12}$

In six studies,9-12,14 the authors considered the influence of social factors on prognosis. All reported that marital status and living circumstances were not related to course and outcome. Post ${ }^{6}$ examined employment, number of social contacts, changes in living circumstances, income and activities and concluded that favourable social circumstances at the time of admission or favourable social changes were linked with good outcome in only a few instances. Murphy ${ }^{9}$ reported that property ownership was related to good outcome, severe intervening life events were related to poor outcome, and social class, precipitating severe life events, major social difficulties and the presence of an intimate, confiding relationship were not related to outcome.

The treatments described and the proportion of patients with a favourable outcome in each of the studies are in Table 4.

\section{Discussion}

This review had a number of limitations in the selection, assessment of validity and examination of the results of the studies. A search strategy involving different databases in other languages with different key words and time periods might have resulted in a different set of articles. Furthermore, different inclu- sion criteria might have been used, and the consistency with which the bibliographies were reviewed and inclusion criteria applied might have been quantified. Finally, the degree of publication bias (tendency to publish reports with "significant" findings) was not assessed, but this type of bias probably had little influence on the publication of studies of prognosis.

With respect to the validity assessment the McMaster criteria ${ }^{18}$ were arguably too rigorous for the studies. For example, description' of referral patterns and blind outcome assessment may have been unnecessary. On the other hand, the criteria were arguably not rigorous enough and could have included additional items concerning explicit diagnostic criteria, minimum severity of depression for inclusion, prospective collection of data, minimum length of follow-up and definition of the follow-up interval (i.e., Does the interval begin on entry to the study, on discharge from hospital or at the end of active treatment?). In addition, the criteria could have described a method of classifying patients who die during follow-up - whether they should be mixed into outcome categories with the living (according to prognosis until the time of death) or be placed in separate categories. Interestingly, Godber and associates ${ }^{13}$ classified living and dead subjects separately into outcome categories and found very similar outcomes in the two groups.

Some of the criteria may have been met by other types of information. For example, the absence of a description of referral pattern may have been offset by a detailed description of the patient population (e.g., quality and quantity of depressive symptoms, cognitive impairment, physical illness and functional disability).

Ideally, the validity should have been assessed by at least one other reviewer, each of us blinded to the other's decision. Also, the extent of the agreement should have been recorded. In this review the validity was assessed only by me; however, the assessment criteria were relatively simple and did not require considerable judgement in their application. Some of the validity criteria were not met because information presented in the reports was

\begin{tabular}{|c|c|c|c|c|}
\hline \multirow[b]{3}{*}{$\begin{array}{l}\text { Prognosis } \\
\text { category }\end{array}$} & \multicolumn{4}{|c|}{ Length of follow-up; \% of patients } \\
\hline & \multicolumn{2}{|c|}{$\leq 24 \mathrm{mo}$} & \multicolumn{2}{|c|}{$>24 \mathrm{mo}$} \\
\hline & Results & $\begin{array}{l}\text { Combined results } \\
(n=575)\end{array}$ & Results & $\begin{array}{l}\text { Combined results } \\
\qquad(\mathrm{n}=515)\end{array}$ \\
\hline Well & $31-64$ & 43.7 & $18-33$ & 27.4 \\
\hline Relapse with recovery & $15-25$ & 15.8 & $28-52$ & 34.2 \\
\hline Continuously ill & $18-69$ & 27.3 & $7-30$ & 9.9 \\
\hline Other & $8-21$ & 13.2 & $23-39$ & 28.5 \\
\hline
\end{tabular}


inadequate; this information (e.g., description of referral patterns) might have been available from the authors of the reports, but they were not contacted.

My examination of the results was complicated not only by the questionable validity of the studies but also by the differences in the length of follow-up and in the outcome categories from one study to the next. Even combining the results in a meta-analysis was controversial, but given the gross similarities in the study designs, probable populations and some of the outcome categories it seemed reasonable.

The numbers of patients in each of the four outcome categories were distressingly varied (Table $3)$. For example, in the group whose follow-up was 24 months or less $31 \%$ to $64 \%$ of the patients remained well. Although the variations can probably be attributed mostly to differences in the three basic study components (population, intervention and outcome measures) none of these components was described well enough to enable comparison, contrast or explanation of the differences.
The combined results of the studies were more useful. In comparing the short-term and long-term follow-up groups I found that the proportion of subjects in the "well" category declined $16.3 \%$ in the short-term follow-up group and $27.4 \%$ in the other. Interestingly, the proportion of subjects in the "relapse with recovery" group increased $18.4 \%$ and $34.2 \%$ respectively. It seems that in both the shortterm and the long-term follow-up groups approximately $60 \%$ of the patients remained well or had relapses with recovery. Given that most of the inception cohorts included subjects with multiple previous depressive episodes, that most of the referrals were to secondary or tertiary rather than primary care settings and that extraneous and negative prognostic factors (i.e., cognitive impairment, physical illness and severity of depression) were not eliminated in most of the studies, my estimate of $60 \%$ probably underestimates the true proportion of patients with a favourable prognosis.

For the same reasons the proportion of subjects

\begin{tabular}{|c|c|c|}
\hline Study & Treatment and $\%$ of patients & $\begin{array}{c}\text { Favourable outcome } \\
\% \text { of patients }\end{array}$ \\
\hline Kay et $\mathrm{al}^{5}$ & Not described & 56 \\
\hline Post $^{6}$ & $\begin{array}{l}\text { Electroconvulsive therapy (ECT) } \\
51.9, \text { routine } 46.9 \\
\text { psychotropic drugs } 1.2\end{array}$ & 59 \\
\hline Post ${ }^{7}$ & $\begin{array}{l}\text { Psychotropic drugs } 80.5 \text {, } \\
\text { ECT } 17.4 \text {, routine } 2.1\end{array}$ & 63 \\
\hline Gordon ${ }^{8}$ & $\begin{array}{l}\text { Combined medical, milieu and } \\
\text { behaviour therapies with } \\
\text { psychotropic drugs, and ECT } \\
\text { (in } 5 \% \text { of cases); aftercare } \\
\text { as indicated }\end{array}$ & 64 \\
\hline Murphy ${ }^{9}$ & ECT $16^{*}$ & $35-54$ \\
\hline $\mathrm{Cole}^{10}$ & $\begin{array}{l}\text { Tricyclics alone } 55 \text {, tricyclics } \\
\text { or monoamine oxidase inhibitors } \\
\text { with or without neuroleptics, } \\
\text { lithium, ECT or sleep } \\
\text { deprivation } 45\end{array}$ & 66 \\
\hline Cole $^{11}$ & $\begin{array}{l}\text { Antidepressants and } \\
\text { psychotherapy } 100 \text {, maintenance } \\
\text { antidepressants } 51\end{array}$ & 70 \\
\hline $\begin{array}{l}\text { Baldwin } \\
\text { et al }{ }^{12}\end{array}$ & $\begin{array}{l}\text { Nine ECT sessions on average plus } \\
\text { psychotropic drugs } 48 \text {, anti- } \\
\text { depressants alone } 45 ;^{*} \text { all } \\
\text { received aftercare: maintenance } \\
\text { antidepressants } 38, \\
\text { antidepressants as needed } 19, \\
\text { little medication } 43\end{array}$ & $\begin{array}{c}58-73+ \\
61 \ddagger\end{array}$ \\
\hline $\begin{array}{l}\text { Godber } \\
\text { et } \mathrm{al}^{13}\end{array}$ & $\begin{array}{l}\text { ECT and antidepressants in most } \\
\text { cases }\end{array}$ & 61 \\
\hline $\begin{array}{l}\text { Magni } \\
\text { et } \mathrm{al}^{14}\end{array}$ & $\begin{array}{l}\text { Tricyclics with or without } \\
\text { anxiolytics, neuroleptics or } \\
\text { lithium in all cases }\end{array}$ & 31 \\
\hline
\end{tabular}


in the "continuously ill" category in the short-term follow-up group is probably an overestimate. In the long-term follow-up group it is impossible to know whether the proportion in this category declined because some of the patients had recovered or because some had been placed in the "other" category. Whatever the explanation the large proportion of "continuously ill" subjects in the short-term followup group represents considerable depressive illness. These patients should probably be involved in independent investigations to determine the factors that cause and those that sustain chronic mood disorder in the elderly.

Physical illness, severity of depressive symptoms and cognitive impairment were frequently associated with poor prognosis. The social factors (excluding severe intervening life events) were not associated with prognosis. More reliable, valid and responsive measures of all prognostic factors are needed to enable more sophisticated analyses of the relation between prognostic factors and the course of depressive illness.

The relation of treatments to prognosis is unclear. None of the studies examined this, and the comparison of treatments and outcomes was difficult because the treatments were poorly described, the outcome categories dissimilar and the follow-up periods unequal. None the less, when only the outcomes of the studies conducted over the past 40 years are compared there is no evidence that the new treatments introduced during this period (e.g., antidepressant drugs and expanded psychogeriatric services) appreciably changed the prognosis.

\section{Recommendations}

These 10 studies have made an important contribution to the knowledge of the prognosis of depression in the elderly, but to advance this knowledge future studies should pay attention to the following recommendations.

- Depressed elderly subjects should be selected from community samples. If they are selected from hospital or clinic populations referral patterns should be described in detail.

- The subjects should be assigned to categories on the basis of previous history of depression (e.g., no or one previous episode versus two or more previous episodes).

- The selection criteria should include explicit diagnostic criteria and minimum severity of depression criteria.

- Important characteristics of the subjects and possible prognostic factors (e.g., depressive symptoms, physical illness, disability, cognition and social factors) should be described using valid and reliable measures.
- The minimum follow-up period for all patients should be 2 years. The follow-up interval should begin on entry to the study.

- Descriptions of the depression outcome categories should be specific and clearly independent of one another. If possible, the proportion of time the subjects are well during the follow-up period should be calculated.

- The assessments of outcome should be blind.

- All treatments should be recorded in detail and related to course of illness and outcome.

- The subjects should be further categorized on the basis of the presence or absence of severe physical illness (or disability) and cognitive impairment. The prognosis of each category could be reported independently.

- All phases of the study (e.g., selection of subjects, diagnosis, use of outcome measures and categorization of outcomes) should have demonstrated reliability.

\section{References}

1. Kraepelin E: Manic Depressive Insanity and Paranoia, Ayer, Salem, NH, 1987

2. Millard P: Depression in old age. Br Med J 1983; 267: 375376

3. Baldwin R: Late life depression: Undertreated [E]? $\mathrm{Br} \mathrm{Med} \mathrm{J}$ 1988; 296: 519

4. Oxman AD, Guyatt GH: Guidelines for reading literature reviews. Can Med Assoc J 1988; 138: 697-703

5. Kay D, Roth M, Hopkins B: Affective disorders in the senium: their association with organic cerebral degeneration. J Ment Sci 1955; 101: 302-316

6. Post F: The Significance of Affective Symptoms in Old Age (Maudsley monogr 10), Oxford U Pr, London, 1962

7. Idem: The management and nature of depressive illness in late life: a follow-through study. Br J Psychiatry 1972; 121: 393-404

8. Gordon WF: Elderly depressives: treatment and follow-up. Can J Psychiatry 1981; 26: 110-113

9. Murphy E: The prognosis of depression in old age. $\mathrm{Br} J$ Psychiatry 1983; 142: 111-119

10. Cole MG: Age, age of onset and course of primary depressive illness in the elderly. Can J Psychiatry 1983; 28: 102-104

11. Idem: The course of elderly depressed outpatients. Can $J$ Psychiatry 1985; 30: 217-220

12. Baldwin R, Jolley D: The prognosis of depression in old age. Br J Psychiatry 1986; 149: 574-583

13. Godber C, Rosenwinge H, Wilkinson D et al: Depression in old age: prognosis after ECT. Int J Geriatr Psychiatry 1987; 2: 19-24

14. Magni G, Palazzolo O, Bianchin G: The course of depression in elderly outpatients. Can J Psychiatry 1988; 33: 21-24

15. Roth $\mathrm{M}$ : The natural history of mental disorder in old age. $J$ Ment Sci 1955; 101: 281-301

16. Feighner J, Robbins E, Guze $S$ et al: Diagnostic criteria for use in psychiatric research. Arch Gen Psychiatry 1972; 26: 5763

17. Diagnostic and Statistical Manual of Mental Disorders, 3rd ed, Am Psychiatr Assoc, Washington, 1980

18. Department of Clinical Epidemiology and Biostatistics, McMaster University Health Sciences Centre: How to read clinical journals: 3 . To learn the clinical course and prognosis of disease. Can Med Assoc J 1981; 124: 869-872 